\title{
General practitioners and the treatment of myocardial infarction: the place of thrombolytic treatment
}

\author{
M C Colquhoun
}

The management of acute myocardial infarction has been revolutionised by thrombolytic therapy, and clinical trials report better results with earlier treatment. ${ }^{1-4}$ Most heart attacks start at home, and studies in countries where specially staffed coronary ambulances are used have shown that it is practicable to start thrombolytic treatment before the patient reaches hospital..$^{5-8}$ The results of these studies may not be applicable to the United Kingdom where general practitioners provide medical care before hospital admission. Should general practitioners administer thrombolytic agents before hospital admission? Can they respond quickly enough, diagnose the condition accurately, and administer thrombolytic treatment safely? If the answer to these questions is yes, then local geography and the benefits from the time saved will determine how widely thrombolysis is used in primary care.

\section{Summon the general practitioner or dial 999?}

Patients with myocardial infarction reach hospital more quickly when an ambulance is summoned directly than when admission is arranged by a general practitioner..$^{9-12}$ But in the studies that demonstrate this thrombolytic treatment was not given by the general practitioners. Had it been thrombolysis would have occurred much earlier in their patients and it is not possible to say which of the two routes results in earlier thrombolytic treatment.

The mortality of acute infarction is reduced by the optimal treatment of patients before transport to hospital, ${ }^{13}{ }^{14}$ and in the United Kingdom a doctor is usually required because ambulance paramedical staff do not give opiate analgesics or intravenous diuretics. While medically staffed mobile coronary care units remain a rarity patients will be denied this valuable treatment unless they are treated by a general practitioner. There are other disadvantages in instructing patients with chest pain to dial 999; the extra workload generated in hospital might prove formidable, and the large number of inappropriate self-referrals might increase the risk of thrombolysis being given to patients with other conditions.

The main advantage in summoning an ambulance directly is that a defibrillator will be bought to the patient immediately. Cardiac arrest occurs in $5 \%$ of patients with acute infarction while they are being attended by their general practitioner ${ }^{15-17}$ and the rhythm is ventricular fibrillation or tachycardia in over $80 \%$ of cases. ${ }^{18}$ Over half the patients survive if the doctor has a defibrillator ${ }^{18}$ but unfortunately few practices own one. The advantages of the ability to defibrillate are emphasised by the finding of the European Myocardial Infarction Project (EMIP) that ventricular fibrillation was more common in patients given thrombolytic treatment before admission to hospital $(2 \cdot 5 \%$ active treatment v $1.6 \%$ placebo) (D G Julian. Personal communication). The extra nine cardiac arrests per thousand patients treated represents a significant mortality when set against the number of lives likely to be saved by earlier thrombolysis.

The time taken for general practitioners to attend patients is vital; the wide variations that continue to be reported are a source of serious concern, and the reasons for the variation require urgent investigation. (Three surveys published in 1992 reported response times of between 10 and 66 minutes. ${ }^{91116}$ General practitioners who do not have a defibrillator should attend with the ambulance service; the general practitioners' skills should be used to diagnose and stabilise the patient before transport to hospital, with the ambulance defibrillator available throughout. Thrombolytic treatment is a logical extension of the treatment that general practitioners already provide and it could be given in the home as soon as the diagnosis is establishedif the diagnosis is secure it makes little sense to wait.

\section{Time saved and benefits of domiciliary thrombolysis}

Patients treated by mobile coronary care units receive thrombolysis $30 \mathrm{~min}$ to $1 \mathrm{~h}$ earlier than patients treated in hospital ${ }^{6-8}$ and reduced infarct size, increased arterial patency, and improved left ventricular function have been reported as a consequence of earlier treatment (for review see Weston and Fox $\left.{ }^{19}\right)$. Most of these studies have been too small to detect a reduction in mortality as a result of earlier treatment, but the larger EMIP study reported a significant reduction in hospital deaths after pre-hospital treatment 
(D G Julian. Personal communication). Only one trial of thrombolysis, the Grampian Region Early Anistreplase Trial (GREAT, has been reported from general practice).${ }^{16}$ In this study the median response time of the general practitioners was 10 minutes and thrombolytic treatment was given at home 101 minutes after the onset of symptoms (hospital treatment was given 240 minutes after the onset of symptoms). Time was saved mainly because the practitioners' door to needle time (43 minutes) was half that for hospital administration ( 87 minutes), and to this saving could be added the journey to hospital ( 47 minutes). The benefits of earlier treatment reported in GREAT were considerable: three months after trial entry there was a relative reduction in death of $49 \%$ in patients treated at home, with fewer $Q$ wave infarcts in survivors. Benefit was most pronounced when treatment was started within two hours of the onset of symptoms: this was possible in $61 \%$ of patients treated at home but in only $1 \%$ of patients treated in hospital.

Widely different door to needle times are reported from British hospitals, the quickest treatment is given in accident and emergency departments $^{11}$ or where there are special arrangements to expedite treatment. ${ }^{2021}$ The results from GREAT strongly suggest that more widespread treatment by general practitioners would be beneficial where patients face a prolonged journey to hospital or treatment is delayed after arrival. General practitioners would be in a better position to assess the need for treatment outside hospital if the door to needle time of their local hospital were audited and the results published.

Some patients are denied thrombolytic treatment on the unjustifiable grounds of age $^{22}$ or because they are admitted to general wards where thrombolytic agents are not given. More widespread use of thrombolytic agents by general practitioners might enable these patients to receive therapy.

\section{Safety of prehospital thrombolysis}

Serious complications from thrombolytic treatment are uncommon immediately after injection. None of the studies of mobile coronary care units reported bleeding or stroke ${ }^{23}$ before hospital admission. In GREAT no serious side effects occurred before hospital admission. General practitions should be prepared to treat hypotension and bradycardia, however.

\section{Accuracy of diagnosis}

The impressive diagnostic accuracy reported by mobile coronary care units was achieved with specially trained personnel using computerised or trans-telephonic electrocardiogram interpretation. ${ }^{24-27}$ The electrocardiogram is the only diagnostic test that can confirm the diagnosis when the general practitioner sees the patient. None the less, few general practitioners use electrocardiography to diagnose acute infarction. ${ }^{2829}$ Though the electrocardiogram may be normal or show minor changes in the early stages of infarction, it should be recorded before thrombolytic therapy is started and it may show unequivocal evidence of infarction and enable treatment to be given with confidence. If it is normal (and general practitioners are good at recognising a normal electrocardiogram (Colquhoun MC, Pitcher DW. Unpublished) the general practitioner need not instigate treatment because the major trials show that patients with a normal electrocardiogram do not benefit from thrombolysis. In GREAT an electrocardiogram was recorded, though trial entry did not depend on electrocardiographic criteria. The general practitioners in this trial were accurate in their diagnoses. The diagnosis of myocardial infarction proved incorrect in only $2 \%$ of cases, and in only $1 \%$ of cases was the admitting doctor able to make an alternative diagnosis.

\section{Conclusions}

Thrombolysis before hospital admission could become widespread practice in the British Isles in the near future if general practitioners were to administer the treatment. Initial experience has shown that general practitioners select appropriate patients for treatment and that significant time saving is possible. Thrombolysis is an extension of the treatment that general practitioners already provide for patients with acute infarction and they should initiate treatment when the diagnosis is certain, especially where the journey to hospital is prolonged or treatment in the local hospital might be delayed.

1 Gruppo Italiano per lo Studio della Streptochinasi nell'Infarto Miocardico (GISSI). Effectiveness of intravenous thrombolytic treatment in acute myocardial infarction. Lancet 1986;i:397-401.

2 Second international study of infarct survival collaborative group. Randomised trial of intravenous streptokinase, oral aspirin, both, or neither among 17,187 cases of suspected acute myocardial infarction: ISIS-2 Lancet 1988 ; i: $1349-60$.

3 The ISAM study group. A prospective trial of intravenous streptokinase in acute myocardial infarction (ISAM). Mortality, morbidity and infarct size at 21 days. $N$ Engl f Med 1986;314:1465-71.

4 The Thrombolysis Early in Acute Heart Attack Group (TEAHEAT). Very early thrombolytic therapy in suspected acute myocardial infarction. Am $f$ Cardiol 1990; pected acu

5 Koren G, Weiss AT, Hasin Y, et al. Prevention of myocardial damage in acute myocardial ischaemia by early treatmen

6 Roth A, Barbash GI, Hod H, et al. Should thrombolytic therapy be administered in the mobile intensive care unit in patients with evolving myocardial infarction? A pilot study. $\mathcal{F}$ Am Coll Cardiol 1990;15:932-6.

7 European Myocardial Infarction Project (EMIP) Subcommittee. Potential time saving with pre-hospital intervention in acute myocardial infarction. Eur Heart $\mathcal{F}$ 1988:9:118-24.

8 Weaver WD, Eisenberg MS, Martin JS, et al. Myocardial Infarction Intervention and Triage Project-Phase 1: patient characteristics and feasibility of prehospital initiation of thrombolytic therapy. $¥ \mathrm{Am}$ Coll Cardiol 1990; 15:925-30.

9 Ahmad RAS, Bond S, Burke J, et al. Patients with suspected myocardial infarction: effect of mode of referral on admission time

10 Armstrong A, Duncan B, Oliver MF, et al. Natural history of acute coronary heart attacks. A community study. $\mathrm{Br}$

11 Birkhead JS. Time delays in provision of thrombolytic treatment in six district hospitals. $B M 7$ 1992;305:445-8. 12 Rowley JM, Mounser P, Harrison EA, et al. Management 
of myocardial infarction: implications for current policy derived from the Nottingham Heart Attack Register. $B$ Heart F 1992;67:255-62.

13 Pantridge JF. The effect of early therapy on hospital mortality from acute myocardial infarction. $Q \mathcal{F}$ Med 1970 39:621-2.

14 Crampton RS, Aldrich RF, Gascho JA, et al. Reduction of prehospital, ambulance and community coronary death rates by the community-wide emergency cardiac care system. Am F Med 1975;58:151-65.

15 Pai GR, Haites NE, Rawles JM. One thousand heart attacks in the Grampian: the place of cardiopulmonary resuscitation in general practice. BMf 1987;294:352-4.

16 Rawles JM 1992. The GREAT group. Feasibility, safety, and efficacy of domiciliary thrombolysis by general pracand efficacy of domiciliary thrombolysis by general prac-
titioners: Grampian region early anistreplase trial. $B M \mathcal{F}$
1992;305:548-53.

17 Rawlins DC. Study of the management of suspected cardiac infarction by British immediate care doctors. $B M \mathcal{J}$ $1981 ; 282: 1677-9$

18 Colquhoun MC, Julian DG. Treatable arrhythmias in cardiac arrests seen outside hospital. Lancet 1992;339. 1167.

19 Weston C, Fox KAA. Prehospital thrombolysis: current status and future prospects. $\mathcal{F} R$ Coll Physicians Lond 1991;25:312-20.

20 Pell ACH, Millar HC, Robertson CE, et al. Effect of "fast track" admission for acute myocardial infarction on delay to thrombolysis. $B M F$ 1992;304:83-7.

21 Burns JMA, Hogg KJ, Rae AP, et al. Impact of a policy of direct admission to a coronary care unit on use of thrombolytic treatment. Br Heart f 1989;61:322-5.

22 Elder AT, Fox KAA. Thrombolytic treatment for elderly patients. BMF 1992;305:846-7.

23 De Jaegrere $\mathrm{P}$, Balk A, Simoons ML. Intracranial haemorrhage and thrombolytic therapy [abstr]. Eur Heart $\mathcal{f}$ 1990;11(suppl): 147 .

24 Castaigne AD, Herve C, Douval-Moulin A-D, et al. Prehospital use of APSAC: results of a placebo-controlled study. Am f Cardiol 1989;64:30A-33A.

25 Kokott N, Rutsch W, Berghofer, et al. Prehospital treatment with IV rt-PA in acute myocardial infarction ment with IV rt-PA in acute myocar

26 Hooghoudt TEH, Hertzberger DP, Hulst $\mathrm{R}$, et al. Prehospital thrombolysis is feasible, safe and reduces time to treatment considerably [abstr]. Eur Heart $\mathcal{f}$ 1990;11(suppl):356

27 Hartman JAM, Bouten MJM, Simoons ML. Prehospital thrombolysis: the nurse experience [abstr]. Eur Heart $\mathcal{f}$ 1990;11(suppl): 154

28 Colquhoun MC. General practitioners' use of electrocardiography: relevance to early thrombolytic treatment. $B M \mathcal{1}$ 1989;299:433.

29 Rawles JM. General practitioners, management of acute myocardial infarction and cardiac arrest: relevance to myocardial infarction and cardiac arrest: relevance
early thrombolytic treatment. $B M \mathcal{F}$ 1987;295:639-40. 